https://russjcardiol.elpub.ru

doi:10.15829/1560-4071-2021-4323

ISSN 1560-4071 (print)

ISSN 2618-7620 (online)

\title{
The role of SGLT2 inhibitors beyond glucose-lowering to cardio-renal protection
}

Karalliedde J.

People with type 2 diabetes mellitus (T2DM) are at high risk of developing cardiovascular disease (CVD) and kidney disease. This enhanced cardio-renal risk persists despite improvements in care and treatments over the last 20 years. Intensive glucose control alone does not substantially reduce the risk of CVD and end stage kidney disease (ESKD).

However, in 2015 the landmark EMPA-REG trial demonstrated for the first time the benefits of Empagliflozin a sodium-glucose co-transporter 2 (SGLT2) inhibitor on CVD events and mortality in people with T2DM. Since this trial several other SGLT2 Inhibitors including Dapagliflozin and Canagliflozin have demonstrated CVD benefits. SGLT2 inhibitors have also demonstrated significant reductions in the risk of hospitalization for heart failure (HHF) and ESKD.

As a consequence of this growing evidence, there has been a shift in the focus of care in T2DM from glucose management to preservation of organ function. SGLT2 inhibitors have emerged as key treatment to reduce CVD, HHF and prevent progression of kidney disease. The benefits for reducing HHF and preventing ESKD have been observed in people with and without T2DM in large randomised controlled clinical trials. In T2DM the positive effects of SGLT2 inhibitors occur early and are independent of their glucose lowering effects.

It is vital that all clinicians recognise the remarkable benefits of SGLT2 inhibitors and use this important class of drugs promptly and early to prevent CVD, HHF and ESKD

Keywords: cardiovascular disease, hospitalization for heart failure, end stage kidney disease.

\author{
Relationships and Activities: none.
}

Guy's and St Thomas Hospital London and School of Cardiovascular Medicine and Sciences, King's College London, London, UK.

Karalliedde J. - Dr, FRCP PhD, Consultant in Diabetes, Endocrinology and Internal Medicine, ORCID: 0000-0002-2617-8320.

\section{Corresponding author: j.karalliedde@kcl.ac.uk}

CKD - chronic kidney disease, $\mathrm{Cl}$ - confidence interval, CV - cardiovascular, CVD - cardiovascular disease, HF - heart failure, CVOTs - cardiovascular outcomes trials, EF - ejection fraction, eGFR - primary renal composite endpoint, ESKD - end-stage kidney disease, $\mathrm{HbA}_{1 \mathrm{c}}$ - glycaemia, $\mathrm{HFrEF}$ - heart failure with reduced ejection fraction, HHF - risk of hospitalization for heart failure, HR hazard ratio, SGLT2 - sodium glucose cotransporter 2, SGLTs - sodium glucose cotransporters, T2DM - type 2 diabetes mellitus.

Received: 29.01.2021

Revision Received: 06.02.2021

Accepted: 19.02 .2021

(c)) BY 4.0

For citation: Karalliedde J. The role of SGLT2 inhibitors beyond glucose-lowering to cardio-renal protection. Russian Journal of Cardiology. 2021;26(3):4323. (In Russ.) doi:10.15829/1560-4071-2021-4323

\section{Кардио- и нефропротективные эффекты глифлозинов помимо снижения уровня гликемии}

Karalliedde J.

Пациенты с сахарным диабетом 2 типа (СД2) подвержены высокому риску развития сердечно-сосудистых (СС3) и почечных заболеваний. Данный риск до сих пор актуален, несмотря на достижения в медицине за последние 20 лет. Сам по себе интенсивный гликемический контроль существенно не снижает риск ССЗ и терминальной хронической болезни почек (ХБП).

Однако в 2015 году крупное исследование EMPA-REG впервые продемонстрировало преимущества эмпаглифлозина, ингибитора натрий-глюкозного котранспортера 2-го типа (SGLT2), в отношении сердечно-сосудистых событий и смертности у пациентов с СД2. После данного исследования несколько других ингибиторов SGLT-2, включая дапаглифлозин и канаглифлозин, также показали значимую эффективность в отношении CC3. Ингибиторы SGLT-2 также продемонстрировали значительное снижение риска госпитализации по поводу сердечной недостаточности $(\mathrm{CH})$ и терминальной ХБП.

Вследствие этого растущего числа данных произошло смещение акцента в лечении СД2 от контроля уровня глюкозы к сохранению функции органов. Ингибиторы SGLT-2 стали ключевым инструментом в лечении CC3 и снижении прогрессирования ХБП. Результаты крупных рандомизированных контролируемых исследований, в которых были включены пациенты с и без СД2, показали, что терапия с использованием глифлозинов связана со снижением уровня госпитализаций по поводу СН и прогрессирования ХБП. При СД2 положительные эффекты ингибиторов SGLT-2 проявляются рано и не зависят от влияния на снижение уровня гликемии.

Особенно важно, чтобы все практикующие врачи были осведомлены о преимуществах ингибиторов SGLT-2 и назначали данный класс препаратов па- циентам на ранней стадии для предотвращения ССЗ, ХБП и снижения риска госпитализаций по поводу $\mathrm{CH}$.

Ключевые слова: сердечно-сосудистые заболевания, госпитализация по поводу сердечной недостаточности, терминальная стадия заболевания почек.

\section{Отношения и деятельность: нет.}

Guy's and St Thomas Hospital London and School of Cardiovascular Medicine and Sciences, King's College London, London, UK.

Karalliedde J. - Dr, FRCP PhD, Consultant in Diabetes, Endocrinology and Internal Medicine, ORCID: 0000-0002-2617-8320.

Автор, ответственный за переписку (Corresponding author): j.karalliedde@kcl.ac.uk

Рукопись получена 29.01.2021 Рецензия получена 06.02.2021 Принята к публикации 19.02.2021

Для цитирования: Karalliedde J. Кардио- и нефропротективные эффекты глифлозинов помимо снижения уровня гликемии. Российский кардиологический журнал. 2021;26(3):4323. doi:10.15829/1560-4071-2021-4323 


\section{Introduction}

The importance of the kidney to the pathophysiology of type 2 diabetes mellitus (T2DM) has been appreciated for many decades [1]. However, in recent years key role of renal sodium glucose cotransporters (SGLTs) glucose homeostasis led to the development of a new class of glucose lowering drugs, sodium glucose cotransporter 2 (SGLT2) inhibitor. SGLT2 inhibitors prevent proximal renal tubular renal glucose and sodium reabsorption [1]. The resultant glucoretic and natriuretic effect of SGLT2 inhibitors are associated with reductions in glycaemia $\left(\mathrm{HbA}_{1 \mathrm{c}}\right)$, body weight and systolic blood pressure. Because SGLT2 inhibitors act on the kidney and have no direct effect on beta cells in the pancreas their metabolic effects occur independently of insulin and the risk of hypoglycaemia is very low [1].

The main SGLT2 inhibitors in clinical use in Europe are empagliflozin, dapagliflozin, canagliflozin and ertugliflozin. SGLT2 inhibitors have differing specificity to the different SGLT receptors. Highest selectivity for SGLT2 receptors is observed with empagliflozin (SGLT2:SGLT1 specificity 2,500), with other agents intermediate in SGLT2 receptor specificity (dapagliflozin, 1200; canagliflozin, 200) with sotagliflozin the least selective $(\sim 20)[1,2]$.

\section{Glycaemic effects}

In T2DM all SGLT2 inhibitors show very similar reductions in $\mathrm{HbA}_{1 \mathrm{c}}$ in trials where the agents have been used as monotherapy in drug-naive patients, in combination with other oral agents or insulin. Although the short-term reduction in $\mathrm{HbA}_{1 \mathrm{c}}$ with SGLT2 inhibitors is comparable to that achieved with metformin, sulphonylureas and DPP-IV inhibitors (0.7-1\%), there is evidence that the durability of glycaemic lowering may better with SGLT2 inhibitors compared to these other drug classes $[3,4]$.

\section{Effects on weight}

As compared to other effects of anti-diabetic agents on weight such metformin (weight neutral), sulphonylureas (weight gain) and DPP-IV inhibitors (weight neutral) there is weight loss associated with SGLT inhibitors treatment [4]. Weight loss is related to the glucose excretion promoted by these agents (60-100 g of glucose excreted per day in the urine) and the related calorific loss. There is typically around $2-3 \mathrm{~kg}$ weight reduction observed after 6 months' treatment and there are positive changes in body composition associated with this weight loss with a reduction in total fat mass, visceral and subcutaneous adipose tissue [4].

\section{Blood pressure reduction}

In clinical trials and real-world studies there are consistent sustained reductions in both systolic $(\sim 5 \mathrm{~mm}$ $\mathrm{Hg})$ and diastolic $(\sim 2 \mathrm{~mm} \mathrm{Hg})$ blood pressure with all SGLT2 inhibitors. These effects are likely to be related to the coupling of glucose and sodium reabsorption in the proximal tubule. SGLT2 inhibition leads to both an osmotic diuresis and mild natriuresis and a corresponding reduction in extracellular fluid and plasma volume $[4,5]$. Of importance these blood pressure lowering effects are also observed in people without T2DM [4].

Effects of SGLT2 inhibitors on the cardiovascular (CV) system

T2DM is a major CV risk factor, and is associated with a nearly three-fold excess risk of coronary artery disease including angina, myocardial infarction, stroke and heart failure (HF), in patients with and without established CV disease (CVD) $[6,7]$.

The close inter-relationship between T2DM and CVD has been recognized for many decades. However for many years the focus was largely on glucose control on the assumption that hyperglycaemia promotes CVD and thus it was assumed that intensive glucose control would slow the progression of CVD. The United Kingdom Prospective Diabetes Study (UKPDS) demonstrated the benefits of intensive glucose-lowering therapy in newly diagnosed T2DM on microvascular complications but failed to demonstrate a significantly reduced the risk on macrovascular complications or CVD death compared with conventional therapy at the end of the trial [8]. Similar results were observed in people with T2DM and longer duration of diabetes in the Action to Control Cardiovascular Risk in Diabetes (ACCORD) trial which suggesting that glucose control did not have a beneficial impact on CVD and that intensive glucose lowering may be associated with harm [9].

\section{The paradigm shift in 2015}

The entire treatment landscape in T2DM however changed in 2015 when the first of the modern CV outcomes trials (CVOTs) to show superiority of a glucoselowering therapy over placebo was presented in September 2015. The Empagliflozin, Cardiovascular Outcomes, and Mortality in Type 2 Diabetes (EMPA-REG) study reported not only $\mathrm{CV}$ safety but also a $14 \%$ reduction in the primary composite endpoint of CV death, non-fatal myocardial infarction and non-fatal stroke compared with placebo (the three-point major adverse CV event (MACE) endpoint). In addition, there was a $38 \%$ reduction in risk of $\mathrm{CV}$ death, a $35 \%$ reduction in risk of hospitalization for $\mathrm{HF}(\mathrm{HHF})$ and a $32 \%$ reduction in the risk of death from any cause [10]. These findings were supported subsequently by data from CVOTs assessing the other licenced SGLT2is, canagliflozin, dapagliflozin and ertugliflozin (Canagliflozin Cardiovascular Assessment Study (CANVAS) Program, Dapagliflozin Effect on Cardiovascular Events - Thrombolysis in Myocardial Infarction (DECLARE-TIMI 58) respectively) [11-13].

Table 1 summarises the recent trials with glucose lowering agents on CVD outcomes including HHF.

\section{Importance of $\mathbf{H F}$}

$\mathrm{HF}$ is a major public health issue affecting up to 63 million people worldwide [14], with 1 in 5 people expected to develop HF during their lifetime [15]. T2DM 
Trials with SGLT2 inhibitors demonstrating major adverse cardiovascular events or hospitalization for HF benefit

\begin{tabular}{|l|l|l|l|l|}
\hline Trial $^{\text {a }}$ & $\begin{array}{l}\text { SGLT2 } \\
\text { Inhibitor }\end{array}$ & $\begin{array}{l}\text { CV risk status } \\
\text { of trial population }\end{array}$ & $\begin{array}{l}\text { MACE HR } \\
(95 \% \mathrm{Cl})\end{array}$ \\
\hline EMPA-REG [10] & Empagliflozin & $\geqslant 99 \%$ with CVD & $0.86(0.74-0.99)$ \\
\hline CANVAS Program & Canagliflozin & $66 \%$ with CVD & $0.86(0.75-0.97)$ & $0.65(0.50-0.85)$ \\
\hline DECLARE-TIMI 58 & Dapagliflozin & $41 \%$ with CVD & $0.93(0.84-1.03)$ & $0.67(0.52-0.87)$ \\
\hline VERTIS CV & Ertugliflozin & $100 \%$ with ACVD & $0.97(0.85-1.11)^{\mathrm{b}}$ & $0.70(0.54-0.90)$ \\
\hline
\end{tabular}

Note: ${ }^{a}$ - benefit in MACE or HHF as defined by a HR for which the upper $\mathrm{Cl}$ did not pass $1.00,{ }^{\mathrm{b}}-95.6 \% \mathrm{Cl}$.

Abbreviations: ACVD - atherosclerotic cardiovascular disease, CANVAS - Canagliflozin Cardiovascular Assessment Study, Cl - confidence interval, CKD - chronic kidney disease, CV - cardiovascular, CVD - cardiovascular disease, DECLARE-TIMI 58 - Dapagliflozin Effect on Cardiovascular Events - Thrombolysis in Myocardial Infarction, EMPA-REG - Empagliflozin, Cardiovascular Outcomes, and Mortality in Type 2 Diabetes, SGLT2 - sodium glucose cotransporter 2, VERTIS CV - Evaluation of Ertugliflozin Efficacy and Safety Cardiovascular.

Table 2

Findings of dedicated renal or HF outcomes trials involving SGLT2 inhibitors

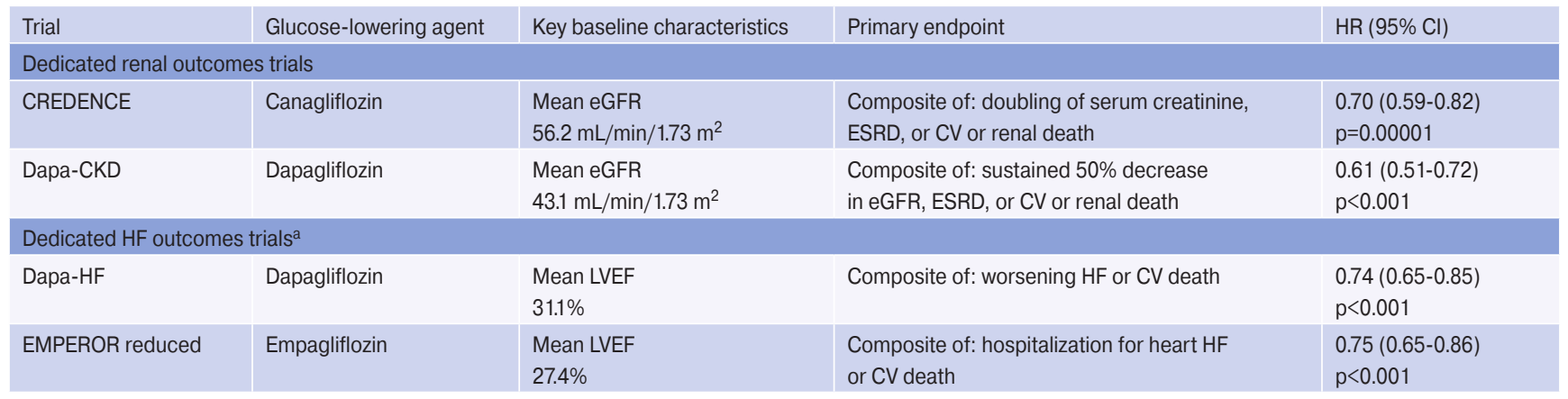

Note: ${ }^{a}$ - trial populations included patients who did not have type 2 diabetes.

Abbreviations: $\mathrm{Cl}$ - confidence interval, CREDENCE - Evaluation of the Effects of Canagliflozin on Renal and Cardiovascular Outcomes in Participants with Diabetic Nephropathy, CV - Cardiovascular, Dapa-CKD - A study to evaluate the effect of dapagliflozin on renal outcomes and Cardiovascular mortality in patients with chronic kidney disease, DAPA-HF - Dapagliflozin and Prevention of Adverse Outcomes in Heart Failure, eGFR - estimated glomerular filtration rate, EMPEROR - Empagliflozin Outcome Trial in Patients with Chronic Heart Failure and a Reduced Ejection Fraction, ESRD - end-stage renal disease, HR - hazard ratio, LVEF - left ventricular ejection fraction.

is a major risk factor for the development of $\mathrm{HF}$ and also a significant adverse prognostic factor in those with established HF $[10,11]$. People with T2DM have a 2-4 times increased risk of developing $\mathrm{HF}$, higher rates of HHF and mortality compared to people with T2DM. Chronic HF is the leading cause of hospitalisation in patients over 65 years old [16], with those hospitalised having a $10 \%, 30$-day and $50 \%, 1$-year mortality. There is also significant economic cost of $\mathrm{HF}$ with an estimated global cost being more than $\$ 100$ billion per year with cost of HHF the major contributing factor. In the Great Britain the average cost for per HHF event is nearly $£ 4000$ ( \$5400) [17].

People with T2DM can develop two distinct phenotypes of HF according to their ejection fraction. Many develop HF with a reduced ejection fraction (EF) $<40 \%$ (HFrEF), which is often characterised by a loss and stretch of cardiac myocytes, left ventricular enlargement and increased serum natriuretic peptides. Treatment of HFrEF encompasses symptomatic control with diuretic treatment accompanied by key treatments that have demonstrated CVD benefits and reduction in HHF (inhibitors of the renin-angiotensin system (including ACE-inhibitors, angiotensin receptor blockers, angiotensin receptor neprilysin inhibitors), beta-blockers and mineralocorticoid receptor antagonists, MRA) [16].

Many people develop HF with preserved ejection fraction ( $\mathrm{EF}>50 \%$; $\mathrm{HFpEF}$ ) which is characterised by systemic and adipose tissue inflammation, microvascular dysfunction and myocardial fibrosis. In contrast to HFrEF patients with HFpEF do not have significantly increased LV size or concentrations of serum natriuretic peptides and show little/no response to neurohormonal antagonists [15, 18]. Observational studies highlight a shifting pattern of the epidemic with the prevalence of HFpEF increasing relative to HFrEF [19], and over time this HFpEF likely to constitute $\sim 65 \%$ of the total $\mathrm{HF}$ burden. This increase is related to the growing prevalence of comorbidities such as T2DM, obesity, hypertension [16].

\section{SGLT2 inhibitors and HF}

Two recent HF outcomes trials: Dapagliflozin and Prevention of Adverse Outcomes in Heart Failure (DAPA-HF); Empagliflozin Outcome Trial in Patients 
Table 3

\section{Summary of adverse effects of SGLT2 Inhibitors and their management}

\begin{tabular}{|c|c|c|c|}
\hline \multirow{4}{*}{$\begin{array}{l}\text { Summary of adverse } \\
\text { effects: } \\
\text { (See summary } \\
\text { of product } \\
\text { characteristics (SmPC) } \\
\text { for full list) }\end{array}$} & Adverse Effect & Frequency & Management \\
\hline & $\begin{array}{l}\text { Creatinine renal clearance decreased } \\
\text { (or serum creatinine increased) during initial } \\
\text { treatment }\end{array}$ & $\begin{array}{l}\text { Common } \\
\text { (or uncommon) }\end{array}$ & $\begin{array}{l}\text { Increases in creatinine are generally transient during continuous } \\
\text { treatment or reversible after discontinuation of treatment. } \\
\text { Suggest monitoring urea \& electrolytes/symptoms more closely } \\
\text { in high-risk persons. }\end{array}$ \\
\hline & Volume depletion & Uncommon & $\begin{array}{l}\text { Monitor patient symptoms, assess severity and consider a break } \\
\text { in treatment until fluid status is back to normal. Advise on hydration }\end{array}$ \\
\hline & $\begin{array}{l}\text { Hypoglycaemia (when used with sulfonylurea } \\
\text { or insulin) }\end{array}$ & $\begin{array}{l}\text { Very } \\
\text { Common }\end{array}$ & $\begin{array}{l}\text { Adjustment of sulfonylurea or insulin dose is needed. Discuss/refer } \\
\text { to patient's diabetes specialist }\end{array}$ \\
\hline \multirow{2}{*}{$\begin{array}{l}\text { Very common }(10 \%) \text {; } \\
\text { Common } \\
\text { (between } 1 \% \text { and }<10 \% \text { ); }\end{array}$} & $\begin{array}{l}\text { Diabetic or euglycaemic ketoacidosis } \\
\text { (when used in type } 2 \text { diabetes mellitus) }\end{array}$ & Rare & Withhold treatment and refer urgently to diabetes team \\
\hline & $\begin{array}{l}\text { Vulvovaginitis, balanitis and related genital } \\
\text { infections }\end{array}$ & Common & $\begin{array}{l}\text { More so in patients with a prior history and females. Advice on hygiene } \\
\text { and topical treatment if symptoms. } \\
\text { Consider interrupting treatment pending investigation. Refer } \\
\text { to GP/gynaecologist if already under one }\end{array}$ \\
\hline \multirow[t]{7}{*}{ Rare $(0.01 \%<0.1 \%)$} & $\begin{array}{l}\text { Vulvovaginal pruritus/ } \\
\text { Pruritus genital }\end{array}$ & Uncommon & $\begin{array}{l}\text { Refer to GP for assessment/treatment if severe. Consider break } \\
\text { in treatment to assess if it is related to SGLT2 inhibitor }\end{array}$ \\
\hline & Fungal infection & Uncommon & $\begin{array}{l}\text { Assess severity and refer to GP for further assessment/for treatment. } \\
\text { If not resolved/further infection develops, consider a break in therapy } \\
\text { to assess association with SGLT2 inhibitor. }\end{array}$ \\
\hline & Urinary tract infection & Common & $\begin{array}{l}\text { More common in females and those with a history. Start treatment - } \\
\text { usually responds well - rarely leads to a need for discontinuation }\end{array}$ \\
\hline & Rash & Common & $\begin{array}{l}\text { Try to eliminate other causes in order to be as sure as possible } \\
\text { that the reaction is due to SGLT2i. If this is likely and there is concern, } \\
\text { consider stopping. }\end{array}$ \\
\hline & Angioedema & Rare & Stop treatment. \\
\hline & Dizziness & Common & \multirow{2}{*}{$\begin{array}{l}\text { Assess severity. Consider if the side effects are tolerable } \\
\text { by the patient, or if they could be treated with other medicines } \\
\text { and refer to GP/other specialist for further assessment/severity. }\end{array}$} \\
\hline & Constipation/Dry mouth & Uncommon & \\
\hline
\end{tabular}

with Chronic Heart Failure and a Reduced Ejection Fraction (EMPEROR-Reduced, Table 2) [20, 21].

The DAPA-HF trial in 4744 patients with New York Heart Association Class 2, 3 or $4 \mathrm{HF}$ and an ejection fraction $40 \%$ or less demonstrated a beneficial effect for dapagliflozin compared with placebo $(26 \%$ relative risk reduction) on the primary outcome of a composite of worsening of HF (hospitalization or an urgent visit resulting in intravenous therapy for HF) or cardiovascular death (hazard ratio (HR) $0.74,95 \%$ confidence interval (CI) 0.65-0.85). Dapagliflozin also had beneficial effects for hospitalization for HF (HR 0.70, 95\% CI, 0.590.83 ) and deaths from cardiovascular causes (HR 0.82, 95\% CI 0.69-0.98). Importantly the beneficial effects on primary outcomes were similar in those with and without T2DM at baseline which was first clear demonstration that SGLT2 inhibitors would have a beneficial impact in people without T2DM [20].

In the recently published EMPEROR-Reduced trial in 3730 patients with New York classification 2, 3 or 4 $\mathrm{HF}$ and ejection fraction less than $40 \%$ were randomized to receive $10 \mathrm{mg}$ empagliflozin or placebo [21]. In this trial a $25 \%$ reduction in the primary composite outcome of cardiovascular death or hospitalization for HF in the empagliflozin group compared with the placebo group (HR 0.75, 95\% CI 0.65-0.86) was observed [21]. Similar to the DAPA-HF findings the beneficial effect of empagliflozin on the primary outcome were consistent regardless of presence or absence of T2DM [21].

Both trials have more similarities than differences and conclusively demonstrated benefits in HFrEF that were similar in patients with and without T2DM. Importantly these positive effects were observed on top of standard of care goal-directed medical therapy including RAS inhibition (sacubitril/valsartan, or ACE-I or angiotensin receptor blockers) beta blockers and mineralocorticoid antagonists. This confirms that the mechanism of effect of SGLT2 inhibitors are distinct from these other established treatment for $\mathrm{HF}$ and are in indeed complementary [22, 23].

A meta-analysis of these two trials comprising 8474 participants demonstrated that SGLT2 inhibitors were associated with a $30 \%$ reduction in all-cause death (HR $0.87,95 \%$ CI $0.77-0.98), 14 \%$ reduction in cardiovascular death (HR $0.86,95 \%$ CI $0.76-0.98$ ) and a $25 \%$ reduction 


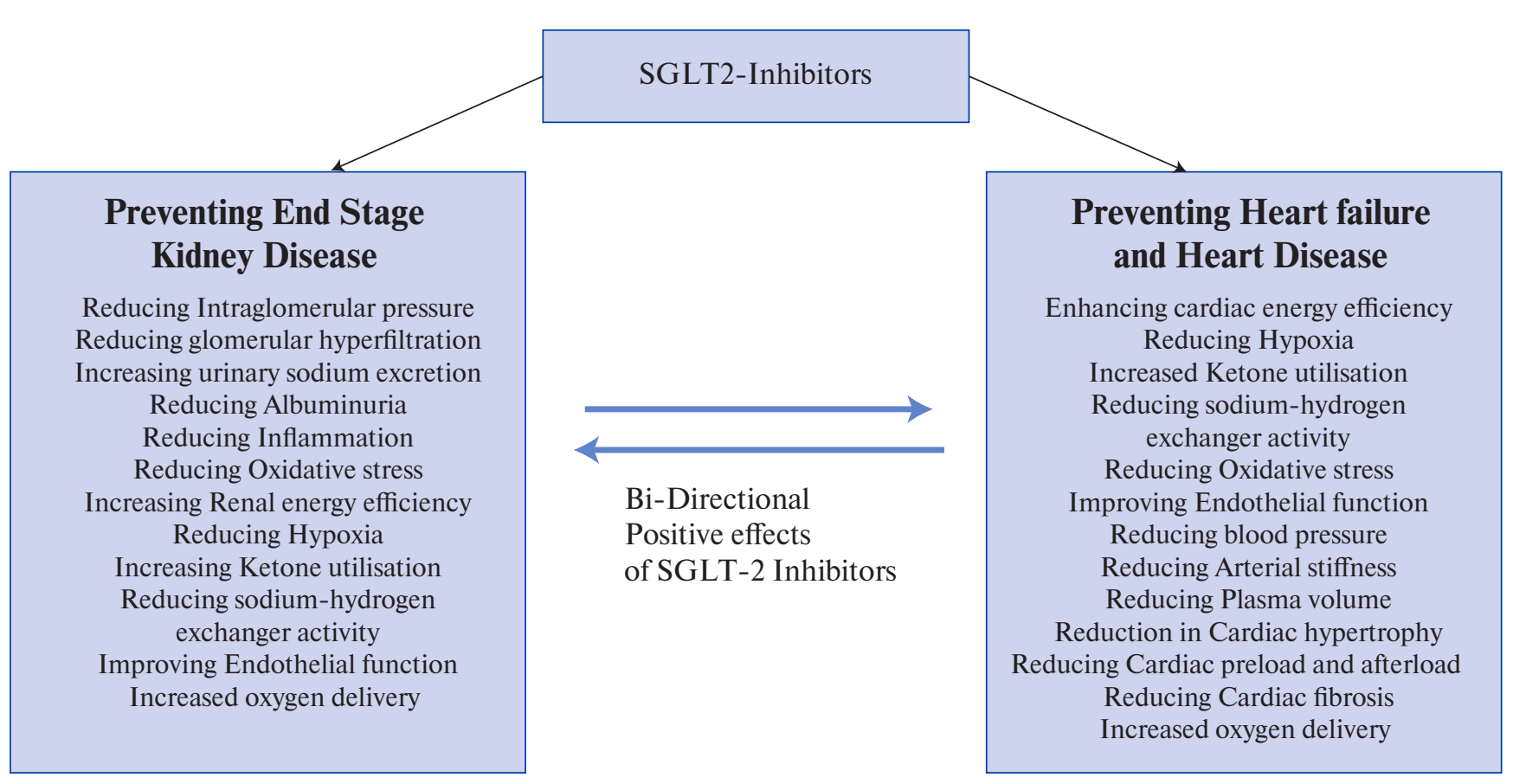

Figure 1. Potential multiple mechanisms by which SGLT2 Inhibitors confer Kidney and Heart protection.

in the composite of recurrent hospitalization for HF or cardiovascular death (HR 0.75, 95\% CI 0.68-0.84), and the risk of a composite renal end point was reduced by $38 \%$ (HR 0.62, 95\% CI 0.43-0.90) [22]. These significant treatment effects were consistent for subgroups of patients based on age, sex, T2DM status and baseline estimated glomerular filtration rate [22].

Potential mechanisms of cardiovascular benefit of SGLT2

The mechanism by which SGLT2 inhibitors reduce $\mathrm{CV}$ death and HF remains unknown, although many theories have been proposed [5]. What is very apparent is fast speed of onset of the cardio-renal benefits of SGLT2 inhibitors and that the proposed mechanisms are not directly related to glucose lowering effects of these medications. Moreover similar benefits for HHF have been observed in those with or without T2DM. Proposed cardiac mechanisms include cardiac remodelling, improved contractility and a shift in myocardial and renal substrate utilisation from fat and glucose oxidation toward an energy-efficient 'super fuel' like ketone bodies, which improve myocardial/renal work efficiency and function, inhibition of sodium-hydrogen exchange, increases in erythropoietin levels, and reduction in myocardial ischemia or reperfusion injury [5, 24]. Figure 1 details the proposed mechanisms by which SGLT2 inhibitors offer cardio-renal protection. What is very clear from the growing literature is that SGLT2 inhibitors are novel neurohormonal antagonists that have remarkable molecular, cellular and clinical mechanism of benefit on the cardiovascular system [24].

\section{Effects of SGLT2 inhibitors on chronic kidney disease (CKD)}

As well as HF, T2DM is frequently complicated by CKD ( $\sim 40 \%$ of people with T2DM). T2DM is the leading cause of end-stage kidney disease (ESKD) globally. T2DM, $\mathrm{CKD}$ and $\mathrm{HF}$ are interconnected and co-exist with nearly $50 \%$ of people with HF have moderate-severe CKD. This co-existence of CKD and HF reflects common pathophysiology such as advancing age, hypertension, coronary artery disease, and type 2 diabetes [25]. Furthermore, the presence of one of these conditions also adversely affect the prognosis of the other. For example, HHF in CKD is associated with a 2-4-fold increased risk of ESKD and the presence of CKD in HF patient is associated with 1-2-fold increased risk increased mortality and 3-4-fold higher rates of HHF [26].

The renoprotective effects of SGLT2 inhibitors in T2DM have been evaluated in five major $\mathrm{CV}$ outcomes trials (CVOTs): EMPA-REG OUTCOME (empagliflozin), CANVAS program, (canagliflozin), DECLARE-TIMI 58 (dapagliflozin), and VERTIS CV (ertugliflozin). In these trials renal endpoints were evaluated as secondary endpoints and all demonstrated SGLT2 inhibitors could prevent the development of CKD and prevent or delay the worsening of CKD in people with T2D at any level of renal risk [27].

Two recent randomised controlled trials with primary renal endpoints have now demonstrated the renal benefits of SGLT2 inhibitors. The Canagliflozin on Renal and Cardiovascular Outcomes in Participants with Diabetic Nephropathy (CREDENCE) and the dapagliflozin on 
renal outcomes and Cardiovascular mortality in patients with chronic kidney disease (Dapa-CKD) [28, 29] (Table 2).

The CREDENCE trial was the first dedicated renal outcomes trial with an SGLT2 inhibitor, in people with CKD and T2D. The relative risk of the primary renal composite endpoint (ESKD, doubling of serum creatinine, or renal or CV death) was $30 \%$ lower in the canagliflozin group than in the placebo group [28].

DAPA-CKD investigated renal outcomes in people with CKD, both with and without T2DM and similar significant reductions in the primary renal composite endpoint (eGFR) $<50 \%$, ESKD, or renal or CV death were observed for patients treated with dapagliflozin compared with placebo, in those with (HR 0.64; $95 \%$ CI 0.52-0.79) and those without T2D (HR 0.50; 95\% CI $0.35-0.72)$ [29].

Multiple mechanisms are likely to explain the observed benefits for renal protection with SGLT2 inhibitors [30, 31]. Figure 1 details the proposed mechanisms by which SGLT2 inhibitors offer cardiorenal protection.

Adverse effects of SGLT2 Inhibitors and how to minimise their impact

The most common adverse effect and how to prevent and manage them if they do occur are listed in Table 3. Genital mycotic infections are common and can be managed with patient education and topical antifungal treatment often [4, 32]. In severe infections not responding to topical treatment temporary suspension of SGLT2 inhibitor maybe required to enable more effective treatment (e.g. oral anti-fungal medication) for the mycotic infection. Although there also be a slightly increased risk of urinary tract infections this however has not been consistently observed in randomised controlled trials. There have been concerns about Fournier's gangrene, a necrotizing fasciitis of the scrotum from safety reporting databases but this adverse event has not observed in large trials to date. There are no current serious or clinically relevant pharmacokinetic interactions between SGLT2i and other medicinal products. Documented interactions are related to the potential effects of synergistic hypotension or hypoglycaemia. Therefore, patients taking drugs with blood pressure or glucose lowering effects concurrently, should have their blood pressure and blood glucose monitored. SGLT2 in-

\section{References}

1. Rieg T, Vallon V. Development of SGLT1 and SGLT2 inhibitors. Diabetologia. 2018;61(10):2079-86. doi:10.1007/s00125-018-4654-7.

2. Ghezzi C, Loo DDF, Wright EM. Physiology of renal glucose handling via SGLT1, SGLT2 and GLUT2. Diabetologia. 2018;61(10):2087-97. doi:10.1007/s00125-0184656-5.

3. Del Prato S, Nauck M, Durán-Garcia S, et al. Long-term glycaemic response and tolerability of dapagliflozin versus a sulphonylurea as add-on therapy to metformin in patients with type 2 diabetes: 4-year data. Diabetes Obes Metab. 2015;17(6):581-90. doi:10.1111/dom.12459. hibitors alone are very unlikely to cause hypoglycaemia. Hypoglycaemia is mostly caused by insulin or sulfonylureas (e.g. gliclazide, glimepiride). In many patients, SGLT2 inhibitors can be started safely without adjustment to other diabetes therapeutics such as metformin. Hypoglycaemia is also unlikely when eGFR $<45 \mathrm{~mL} /$ $\mathrm{min} / 1.73 \mathrm{~m}^{2}$ as the drug's glucose lowering effect is reduced. Some patients are at higher risk of hypoglycaemia, for example if they have a history of previous frequent hypoglycaemic events or if their glycaemic control (estimated by $\mathrm{HbA}_{1 \mathrm{c}}$ ) at baseline is very good and they are already on agents that can cause hypoglycaemia (such as insulin, sulfonylureas. In such high-risk patients, liaison with the diabetes specialist team prior to initiation of SGLT2 is recommended as these patients may need cessation or dose adjustment of their other diabetic medications to enable starting SGLT2 inhibitors.

Diabetic ketoacidosis is a known but rare risk with SGLT2 inhibitors and can occur at normal glucose levels [4]. Suspect diabetic ketoacidosis in patients with nonspecific symptoms such as nausea, vomiting, anorexia, abdominal pain, excessive thirst, difficulty breathing, confusion, unusual fatigue or sleepiness. Patients should be assessed for ketoacidosis immediately if these symptoms occur, regardless of blood glucose level.

\section{Conclusions}

In the last 5 years there has been a paradigm shift in the care of patients with T2DM. The growing evidence for treatments such as SGLT2 inhibitors that offer cardiorenal protection has resulted in this major change. International and national guidelines in cardiology, renal medicine and diabetes have adapted to this evidence and now recommend early use of SGLT2 Inhibitors for the prevention of HF, kidney disease and atherosclerotic cardiovascular disease. Put together, this change in approach has major implications not only for primary care, where the majority of these patients with T2DM, $\mathrm{HF}$ and CKD are often managed, but also for specialist care physicians, including cardiologists, diabetologists, and nephrologists. SGLT2 inhibitors are a unique class that have multiple uses across different medical specialities and will be an essential medication for future management of people with or without established cardiovascular disease, with or without T2DM, patients with renal disease and those with HF.

4. Brown E, Wilding JP, Alam U, et al. The expanding role of SGLT2 inhibitors beyond glucoselowering to cardiorenal protection. Ann Med. 2020:1-32. doi:10.1080/07853890.2020.1841281

5. Heerspink HJ, Perkins BA, Fitchett DH, et al. Sodium Glucose Cotransporter 2 Inhibitors in the Treatment of Diabetes Mellitus: Cardiovascular and Kidney Effects, Potential Mechanisms, and Clinical Applications. Circulation. 2016;134(10):752-72. doi:10.1161/ CIRCULATIONAHA.116.021887.

6. Karalliedde J, Gnudi L. Diabetes mellitus, a complex and heterogeneous disease, and the role of insulin resistance as a determinant of diabetic kidney disease. Nephrol Dial Transplant. 2016;31(2):206-13. doi:10.1093/ndt/gfu405. 
7. Glovaci D, Fan W, Wong ND. Epidemiology of Diabetes Mellitus and Cardiovascular Disease. Curr Cardiol Rep. 2019;21(4):21. doi:10.1007/s11886-019-1107-y.

8. Macisaac RJ, Jerums G. Intensive glucose control and cardiovascular outcomes in type 2 diabetes. Heart Lung Circ. 2011;20(10):647-54. doi:10.1016/j.hlc.2010.07.013.

9. Karalliedde J, Gnudi L. ACCORD and ADVANCE: a tale of two studies on the merits of glycaemic control in type 2 diabetic patients. Nephrol Dial Transplant. 2008;23(6):1796-8. doi:10.1093/ndt/gfn200

10. Zinman B, Wanner C, Lachin JM, et al. Empagliflozin, cardiovascular outcomes, and mortality in type 2 diabetes. N Engl J Med. 2015;373(22):2117-28. doi:10.1056/ NEJMoa1504720.

11. Neal B, Perkovic V, Mahaffey KW, et al. Canagliflozin and cardiovascular and renal events in type 2 diabetes. N Engl J Med. 2017;377(7):644-57. doi:10.1056/NEJMoa1611925.

12. Wiviott SD, Raz I, Bonaca MP, et al. Dapagliflozin and cardiovascular outcomes in type 2 diabetes. N Engl J Med. 2019;380(4):347-57. doi:10.1056/NEJMoa1812389.

13. Cannon CP, Pratley R, Dagogo-Jack S, et al. Cardiovascular Outcomes with Ertugliflozin in Type 2 Diabetes. N Engl J Med. 2020;383(15):1425-35. doi:10.1056/NEJMoa2004967.

14. GBD 2016 Disease and Injury Incidence and Prevalence Collaborators. Global, regional, and national incidence, prevalence, and years lived with disability for 328 diseases and injuries for 195 countries, 1990-2016: a systematic analysis for the Global Burden of Disease Study 2016. Lancet. 2017;390(10100):1211-59. doi:10.1016/S01406736(17)32154-2.

15. Lam CSP, Chandramouli C, Ahooja V, Verma S. SGLT2 Inhibitors in Heart Failure: Current Management, Unmet Needs, and Therapeutic Prospects. J Am Heart Assoc. 2019;8(20):e013389. doi:10.1161/JAHA.119.013389.

16. BraunwaldE. Thewar againstheartfailure: the Lancet lecture. Lancet. 2015;385(9970):81224. doi:10.1016/S0140-6736(14)61889-4.

17. Stewart S, Jenkins A, Buchan S, et al. The current cost of heart failure to the National Health Service in the UK. Eur J Heart Fail. 2002;4(3):361-71. doi:10.1016/s1388-9842(01)00198-2.

18. Ponikowski P, Voors AA, Anker SD, et al. 2016 ESC Guidelines for the diagnosis and treatment of acute and chronic heart failure: The Task Force for the diagnosis and treatment of acute and chronic heart failure of the European Society of Cardiology (ESC) Developed with the special contribution of the Heart Failure Association (HFA) of the ESC. Eur Heart J. 2016;37(27):2129-200. doi:10.1093/eurheartj/ehw128.

19. Tsao CW, Lyass A, Enserro D, et al. Temporal Trends in the Incidence of and Mortality Associated With Heart Failure With Preserved and Reduced Ejection Fraction. JACC Heart Fail. 2018;6(8):678-85. doi:10.1016/j.jchf.2018.03.006

20. McMurray JJV, Solomon SD, Inzucchi SE, et al. Dapagliflozin in Patients with Heart Failure and Reduced Ejection Fraction. N Engl J Med. 2019;381(21):1995-2008. doi:10.1056/ NEJMoa1911303.
21. Packer M, Anker SD, Butler J, et al. Cardiovascular and Renal Outcomes with Empagliflozin in Heart Failure. N Engl J Med. 2020;383(15):1413-24. doi:10.1056/ NEJMoa2022190.

22. Zannad F, Ferreira JP, Pocock SJ, et al. SGLT2 inhibitors in patients with heart failure with reduced ejection fraction: a meta-analysis of the EMPEROR-Reduced and DAPAHF trials. Lancet. 2020;396(10254):819-29. doi:10.1016/S0140-6736(20)31824-9.

23. Vaduganathan $M$, Claggett $B L$, Jhund PS, et al. Estimating lifetime benefits of comprehensive disease-modifying pharmacological therapies in patients with heart failure with reduced ejection fraction: a comparative analysis of three randomised controlled trials. Lancet. 2020;396(10244):121-128. doi:10.1016/S0140-6736(20)30748-0.

24. Packer M. Molecular, Cellular, and Clinical Evidence That Sodium-Glucose Cotransporter 2 Inhibitors Act as Neurohormonal Antagonists When Used for the Treatment of Chronic Heart Failure. J Am Heart Assoc. 2020;9(16):e016270. doi:10.1161/ JAHA.120.016270.

25. Yancy CW, Lopatin M, Stevenson LW, et al. Clinical presentation, management, and in-hospital outcomes of patients admitted with acute decompensated heart failure with preserved systolic function: a report from the Acute Decompensated Heart Failure National Registry (ADHERE) Database. J Am Coll Cardiol. 2006;47(1):76-84. doi:10.1016/j. jacc.2005.09.022.

26. Schefold JC, Filippatos G, Hasenfuss G, et al. Heart failure and kidney dysfunction: epidemiology, mechanisms and management. Nat Rev Nephrol. 2016;12(10):610-23. doi:10.1038/nrneph.2016.113.

27. Neuen BL, Young T, Heerspink HJL, et al. SGLT2 inhibitors for the prevention of kidney failure in patients with type 2 diabetes: a systematic review and meta-analysis. Lancet Diabetes Endocrinol. 2019;7(11):845-54. doi:10.1016/S2213-8587(19)30256-6.

28. Perkovic V, Jardine MJ, Neal B, et al. Canagliflozin and Renal Outcomes in Type 2 Diabetes and Nephropathy. N Engl J Med. 2019;380(24):2295-306. doi:10.1056/ NEJMoa1811744.

29. Heerspink HJL, Stefánsson BV, Correa-Rotter R, et al. Dapagliflozin in Patients with Chronic Kidney Disease. N Engl J Med. 2020;383(15):1436-46. doi:10.1056/NEJMoa2024816. doi:10.1056/NEJMoa2024816

30. Heerspink HJL, Kosiborod M, Inzucchi SE, Cherney DZI. Renoprotective effects of sodium-glucose cotransporter-2 inhibitors. Kidney Int. 2018;94(1):26-39. doi:10.1016/j. kint.2017.12.027.

31. Gnudi L, Karalliedde J. Beat it early: putative renoprotective haemodynamic effects of oral hypoglycaemic agents. Nephrol Dial Transplant. 2016;31(7):1036-43. doi:10.1093/ndt/ gfv093.

32. Halimi $\mathrm{S}$, Vergès B. Adverse effects and safety of SGLT2 inhibitors. Diabetes Metab. 2014;40(6 Suppl 1):S28-34. doi:10.1016/S1262-3636(14)72693-X. 